Distorted static field. Observed annihilation rates [4] are greater than the high energy limit so one must assume considerable atomic distortion.

As a positron approaches an atom from a great distance, the first interaction to take effect is via the electric dipole moment induced in the atom. The interaction energy is

$$
U=e^{2} \alpha / r^{4},
$$

where $\alpha$ is the polarizability of the atom.

There is experimental evidence for the importance of this long range dipole interaction: over a wide range of atomic and molecular gases a correlation has been observed between annihilation rate and dipole polarizability [9].

As the positron gets closer, higher multipoles become important. A stationary state treatment exaggerates the distortion because it takes no account of the inertia of the electron cloud, but is correct for very low energies.

It is possible that attraction of the positron to the atom as a result, at first, of the long range force could end in the positron attaching to the atom. And there is some evidence that this effect has been observed [4] at very low positron energies. Annihilation of an attached positron would be nearly instantaneous, so that here it is the cross-section that should be calculated.

Virtual attachment and virtual positronium formation are ways of describing the short range atomic distortions. The former may be suitable for very low energies, the latter near positroni- um production threshold. Again a stationary calculation of the annihilation rate would provide information for the experimentally interesting case of very low energy.

For a complete interpretation of experimental data, which is in the form of lifetime spectra, one needs the cross-section and the annihilation rate as a function of energy. And whereas previously cross-sections alone have been computed, there would seem to be no great difficulty in obtaining the rates as well.

\section{References}

1) S. J. Tao, J. Bell and J. H. Green, Proc. Phys. Soc. (London) 83 (1964) 453.

2) W. R. Falk and G. Jones, Can. J. Phys. 42 (1964) 1751.

3) D. A. L. Paul, Proc. Phys. Soc. (London) 84 (1964) 563.

4) P. E. Osmon, Phys. Rev. 138 (1965) B216.

5) W. R. Falk, P. H. R. Orth and G. Jones, Phys. Rev. Letters 14 (1965) 447.

6) P. G. Burke and Kenneth Smith, Rev. Mod. Phys. 34 (1962) 458.

7) W.J. Cody, Joan Lawson, Sir Harrie Massey and K. Smith, Proc. Roy. Soc. (London) 278A (1964) 479.

8) K. Smith (private communication).

9) P. E. Osmon (unpublished).

10) W. B. Teutsch and V.W. Hughes, Phys. Rev. 103 (1956) 1261.

\title{
FOURIER-TRANSFORM SPECTROSCOPY USING HOLOGRAPHIC IMAGING WITHOUT COMPUTING AND WITH STATIONARY INTERFEROMETERS
}

\author{
G. W. STROKE and A. T. FUNKHOUSER \\ The University of Michigan, Ann Arbor, Michigan
}

Received 6 May 1965

The remarkable properties and the important advantages of several forms of 'Fourier-transform spectroscopy' have now been established [1-6], following initial work by Jacquinot [4], Fellgett [5], Strong [6] and others $[1,3,6]$. Among the principal advantages are a simultaneous recording of all spectral elements (recording-time independent of the spectral width) and high luminosity. The method requires very accurate (ruling-engine quality) moving-mirror motion (or scanning) and computation (by Fou- rier transformation) of the spectrum from the photoelectrically recorded interferogram. Recent advances in holographic (wavefront-reconstruction) imaging [7-11], and in its Fouriertransform formulation $[7,10,11]$, make it reasonable to investigate possible simplifications which might result from extensions of holography to such applications as spectroscopy and astronomy.

In this letter we demonstrate the theoretical principles and experimental verifications of a 
holographic method of 'Fourier-transform spectroscopy'. The method permits one to obtain the spectrum without any computation, and indeed in an interferometric system having completely stationary elements and medium. Possibilities of using Fresnel-transform holography for the computation of the spectrum, photoelectrically recorded in a scanning interferometer were recently noted by Falconer and Winthrop [12]. In our method, no transcription of a photoelectrically recorded interferogram, nor any scanning are required.

As a model, we discuss the recording of the spectral Fourier-transform hologram in a twobeam interferometer, in which the wavefronts form a small angle $\theta$ with each other. The interference-fringe system photographically recorded in a plane "parallel" to the bisector of the wavefronts is proportional (in the holographic sense) to a non-coherent superposition of the monochromatic fringe systems corresponding to each wavelength $\lambda$. The equation of the fringe system in the plane of the photographic plate is given by

$$
I(x)=\int_{0}^{\infty} I(\sigma)[1+\cos (2 \pi \tau \theta x)] \mathrm{d} \sigma
$$

where $\sigma=1 / \lambda(\mathrm{cm})$ and $I(\sigma)$ is the spectral intensity distribution (the spectrum) of the source. Eq. (1), the cosine Fourier-transform of $I(\sigma)$ is recognized as the equation of the spectral Fourier-transform hologram of $I(\sigma)$ (i. e. a "non-co-

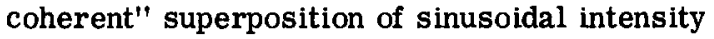
gratings, one per each $\lambda$ ). Consequently, illumination of the hologram by a spatially coherent, monochromatic plane wave will produce in the focal plane of a lens the spectrum $I(\sigma)$, symmet-

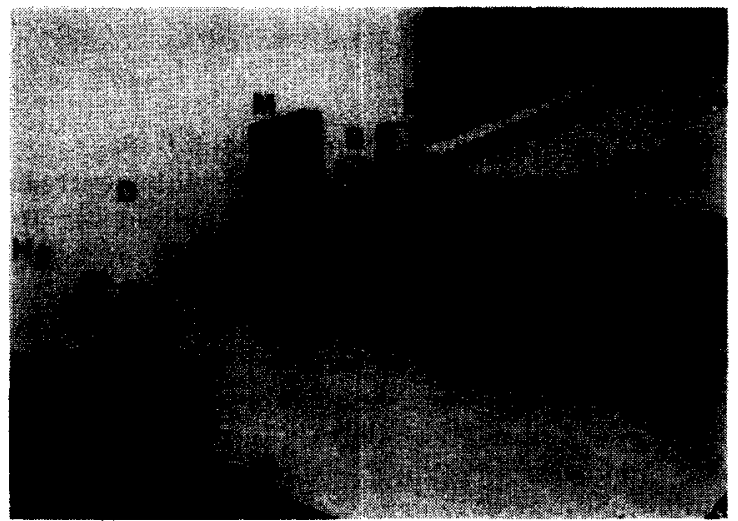

Fig. 1. Interferometer used in recording spectroscopic Fourier-transform hologram $(\mathrm{H})$ of cold mercury arc $(\mathrm{Hg}) . \mathrm{D}=$ diffuser, $M, M=$ interferometer mirrors, $\mathrm{B}=$ beam-splitter. rically displayed on the two sides of the optical axis (one pair of spectral lines for each grating recorded, plus zero-frequency terms).

The compensated Michelson-Twyman-Green interferometer used in our experiments to record the holograms is shown in fig. 1 , and a reconstruction of the spectrum of a cold mercury arc, obtained by illuminating the hologram in $6328 \AA$ laser light is shown in fig. 2. A very wide, diffusely illuminated source "aperture" was used in the recording, with an interferometer wedge of about 30 "white-light (mercury)" fringes per millimeter, near zero-path difference, and with Kodak 649F high-resolution plates. (Aligning experiments were carried out on Polaroid $P / N$ film). (Initial experiments with a flash-light source indicate that a continuous spectrum does produce a recordable interferometric hologram, and a reproducible spectrum). A dualism between the recording of spectral frequencies in holographic spectroscopy and the recording of spatial frequencies in (single-spectral frequency) holographic imaging is readily recognized. A discussion of the limitations, characteristic of holography, associated with the recordability of the interference-fringe components, with special application to spectroscopy, and a comparison

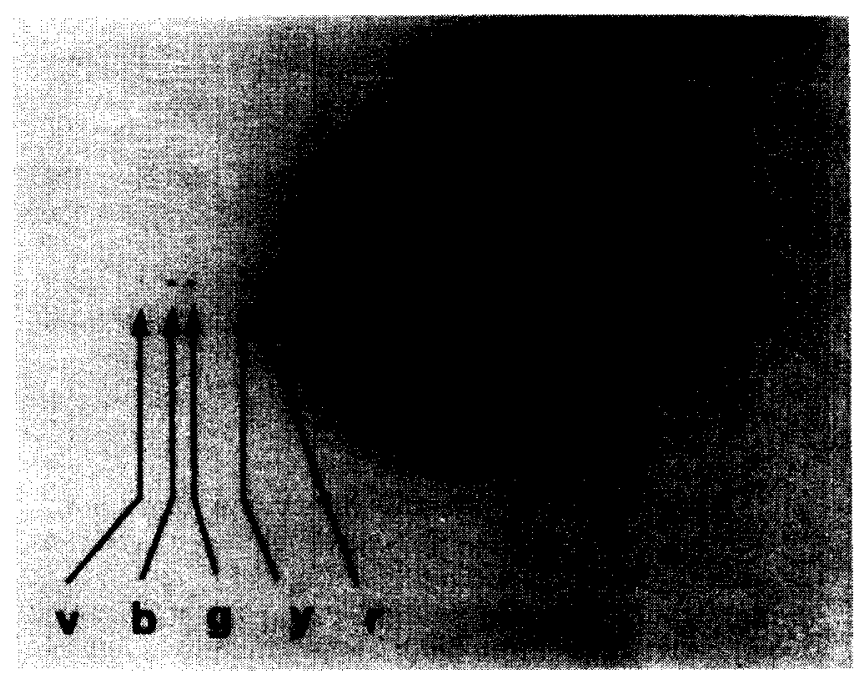

Fig. 2. Spectrum of mercury obtained in the focal plane of a lens by projecting a plane wave of $6328 \AA$ laser light through the spectroscopic Fouriertransform hologram $(\mathrm{H})$ recorded in the interferometer of fig. 1 . Note the symmetrical display of the spectrum into a left and a right sideband, which permits wavelength determination by simple measurement of distance-ratios. Identified, in the left side-band, are the mercury lines [13]: $v(4047 \AA, 4078 \AA), b(4348 \AA$ $4359 \AA), g(5461 \AA), y(5770 \AA, 5790 \AA), r(6152 \AA$, $6234 \AA)$. 
of the "luminosity-resolution" parameters with other methods of spectroscopy, in view of singling out possible areas of application, will be given in a subsequent paper. Among several possible advantages of holographic Fouriertransform spectroscopy appears the possibility of "recording" spectra on a lensless, slitless and completely static interferometric assembly of two mirrors, simply pointed in the general direction of a diffuse source, for instance in astronomy or the study of plasmas.

One of us (GWS) wishes to acknowledge the kind interest, encouragement and many fruitful conversations held with Professor Orren $\mathrm{C}$. Mohler, in regard to this work. We also wish to acknowledge many fruitful conversations with D. Brumm and D. G. Falconer of our laboratory, and of the generous support of NASA and of NSF of parts of this work.

\section{References}

1) e.g. P.Jacquinot, New Developments in Inter- ference Spectroscopy, in Reports on Progress in Physics, Vol. XXII, p. 267 (1960).

2) Colloquium papers of "Les progrès récents en spectroscopie interférentielle", J. Phys. Radium, 19, No. 3 (Mars 1958).

3) J. Connes, Rev. optique 40 (1961) 45, 116, 171, 231.

4) P. Jacquinot and Ch. Dufour, J. Rech. Centre Nat. Rech. Sci. , Lab. Bellevue (Paris), 6 (1948) 91.

5) P. Fellgett, Thesis, University of Cambridge (1951).

6) J. Strong, J. Opt. Soc. Am. 47 (1957) 354.

7) G. W. Stroke and D. G. Falconer, Theoretical and experimental foundations of optical holography (wavefront-reconstruction imaging), in Symp. on optical and electro-optical information processing, J. T. Tippett, L. C. Clapp, D. Berkowitz and C. J. Koester, eds. (M. I. T. Press, 1964) in print.

8) G. W. Stroke and D. G. Falconer, Physics Letters 15 (1965) 238.

9) E. N. Leith and J. Upatnieks, J. Opt. Soc. Am. 55 (1965) 569.

10) G. W. Stroke, Applied Physics Letters, 6, No. 10 (15 May 1965).

11) G.W. Stroke, An introduction to optics of coherent and non-coherent electromagnetic radiations, 2nd edition (The University of Michigan,1965).

12) D. G. Falconer and J. T. Winthrop, Physics Letters, 14 (1965) 190.

13) G. R. Harrison, R. C. Lord and J. R. Loofbourow, Practical Spectroscopy (Prentice Hall, New York, 1949) p. 203.

\title{
ÜBER DIE EIGENENERGIE EINER GEPULSTEN UNTERKRITISCHEN ANORDN UNG
}

\author{
K. -H. MÜLLER \\ CCR Euratom Ispra, Italien
}

Eingegangen am 6. Mai 1965

Beschießt man eine unterkritische Kugel möglichst gleichverteilt mit Neutronen und haben diese eine für die Spaltung "gunstige" Energie, so nimmt möglicherweise die Primärdichte zunăchst zu, wird schließlich nach einer Moderation aber durch parasitare Absorption reduziert. Ein Abstimmen der Startenergie auf den Moderationsvorgang gibt die Chance, mehr Sekundärneutronen auf eine gtinstige Energie zu bringen als zuvor und damit der parasitären Absorption entgegenzuwirken. Der Dichteabfall kann dadurch verzögert oder gar zeitweilig aufgehoben werden. Der Wettlauf zwischen Absorption und Moderation wird im Kugelinnern zugunsten der Moderation, am Kugelrande zugunsten des um den Leck- verlust vermehrten Schwundes beeinflußt.

Bei einer unterkritischen Kugel mit zentralem Punktburst besorgt der Expansionseffekt der Primärneutronen ein Absinken der Primärdichte, zugleich vermag er aber auch eine "gunstige" Raum- und Energieverteilung aufzubauen, bevor die Moderation die Mehrheit der Neutronen auf die gunstige Spaltenergie abgebremst hat.

Kurze Zeit nach erfolgtem Burst gibt bereits das monoenergetische $\mathbf{P}_{1}$-Modell einen Einblick in das charakteristische Zeitverhalten der Neutronendichte $N$. Dies ausniltzend soll einmal die Möglichkeit für ein Extremum im Zeitverlauf abgewogen werden. Ein Extremalwert verlangt notwendig $\partial N / \partial t=0$. Bei positivem Buckling, $\Delta N<0$ 